\title{
The effect of surfactant on clinical outcome of patients with COVID-19 under mechanical ventilation: A structured summary of a study protocol for a randomised controlled trial
}

\author{
Ali Dabbagh ${ }^{1 *}$ D, Samira Rajaei ${ }^{2}$, Mehdi Ghahremani ${ }^{3}$, Mohammad Fathi $^{3}$, Nilofar Massoudi ${ }^{4}$, Sasan Tavana ${ }^{5}$, \\ Kamal Fani ${ }^{6}$, Navid Nooraee ${ }^{3}$, Nasser Malekpour Alamdari', Sara Besharat ${ }^{8}$, Arash Najafi Abrandabadi ${ }^{3}$, \\ Ali Pirsalehi ${ }^{5}$ and Mohammad Ali Khabiri Khatiri ${ }^{3}$
}

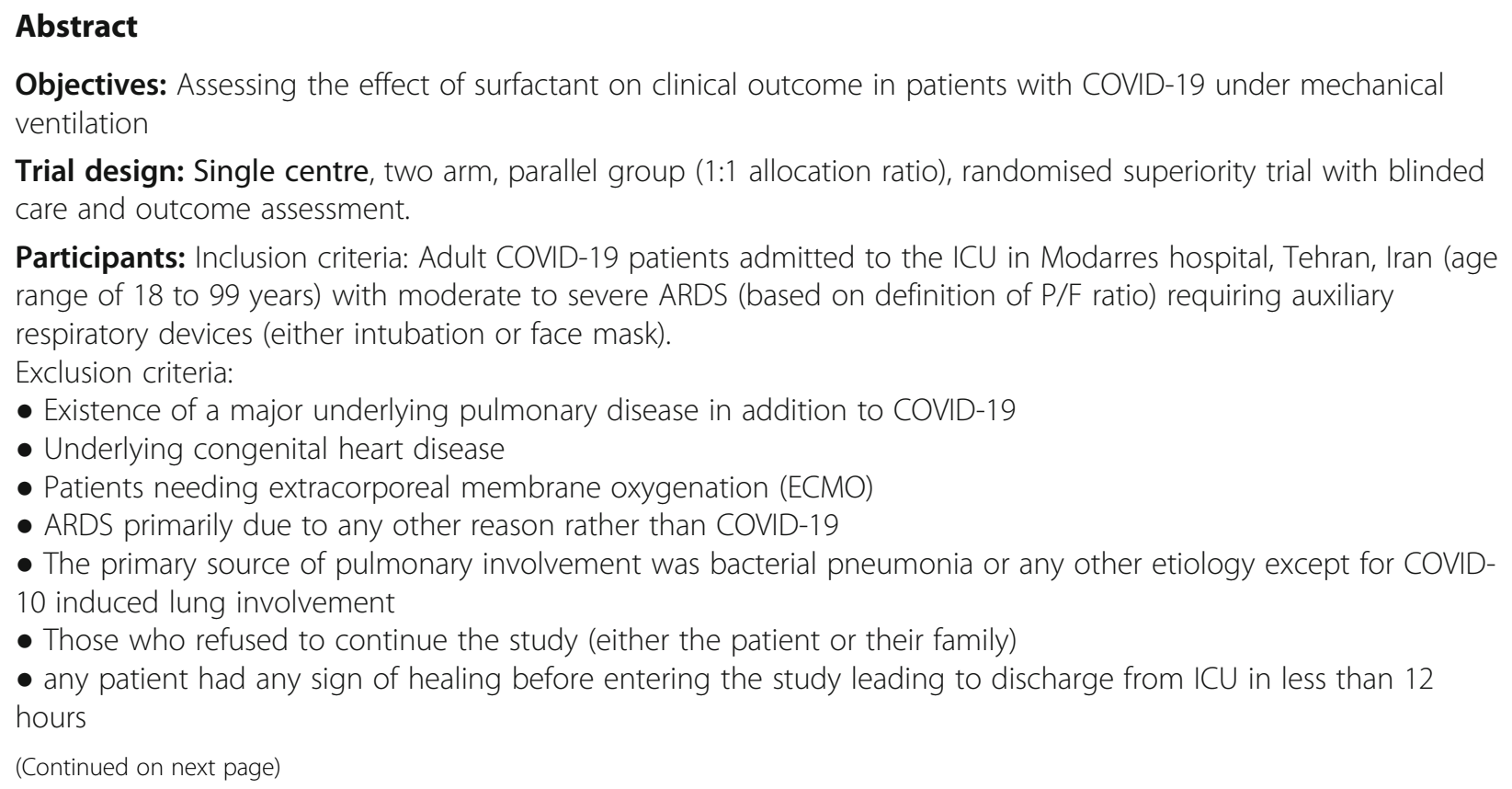

- The primary source of pulmonary involvement was bacterial pneumonia or any other etiology except for COVID10 induced lung involvement

- Those who refused to continue the study (either the patient or their family)

- any patient had any sign of healing before entering the study leading to discharge from ICU in less than 12 hours

\footnotetext{
* Correspondence: alidabbagh@yahoo.com

${ }^{1}$ Cardiac Anesthesiology Department, Anesthesiology Research Center,

School of Medicine, Shahid Beheshti University of Medical Sciences, Tehran,

Iran

Full list of author information is available at the end of the article
}

(c) The Author(s). 2020 Open Access This article is licensed under a Creative Commons Attribution 4.0 International License, which permits use, sharing, adaptation, distribution and reproduction in any medium or format, as long as you give appropriate credit to the original author(s) and the source, provide a link to the Creative Commons licence, and indicate if changes were made. The images or other third party material in this article are included in the article's Creative Commons licence, unless indicated otherwise in a credit line to the material. If material is not included in the article's Creative Commons licence and your intended use is not permitted by statutory regulation or exceeds the permitted use, you will need to obtain permission directly from the copyright holder. To view a copy of this licence, visit http://creativecommons.org/licenses/by/4.0/. The Creative Commons Public Domain Dedication waiver (http://creativecommons.org/publicdomain/zero/1.0/) applies to the data made available in this article, unless otherwise stated in a credit line to the data. 
(Continued from previous page)

Intervention and comparator: In the intervention group, the dose of the drug is a vial containing $4 \mathrm{ml}$, equivalent to $100 \mathrm{mg}$, which is prescribed for an adult weighing about $70 \mathrm{~kg}$ each time, and if the patient's weight is much lower or higher, it will be adjusted accordingly. Surfactant is prescribed inside the trachea in two doses, starting on the day of intubation with a second dose 6 hours later. The control group will receive the same volume of normal saline, based on weight, administered into the trachea with the same time schedule.

Main outcomes: 30 days mortality; patient mortality during stay in ICU up to 30 days; ICU length of stay up to 30 days; Time under mechanical ventilation up to 30 days.

Randomisation: After the participant enters the study, i.e. after the qualification of the patients in the trial is confirmed and their informed written consent is taken, we will use a simple randomisation method using a table of random numbers. In order to hide the random allocation process, a central randomisation approach will be used and the random sequence will be at the disposal of one of the researchers, excluding the principal investigator.

Blinding (masking): Participants, healthcare providers and the principal investigator assessing the outcomes will all be blinded to the group assignment.

Numbers to be randomised (sample size): A total of 60 participants will be randomised in a 1:1 allocation ratio (30 patients allocated to the intervention group and 30 patients allocated to the control group).

Trial Status: The protocol is Version 1.0, May 31, 2020. Recruitment began July 30, 2020, and is anticipated to be completed by October 30, 2020.

Trial registration: IRCT registration number: IRCT20091201002804N12

Registration date: 1st June 2020, 1399/03/12

Full protocol: The full protocol is attached as an additional file, accessible from the Trials website (Additional file 1). In the interest in expediting dissemination of this material, the familiar formatting has been eliminated; this Letter serves as a summary of the key elements of the full protocol.

Keywords: COVID-19, SARS-COV-2, surfactant, ICU, acute respiratory distress syndrome, ventilator, mechanical ventilation; mortality; hospital length of stay; hospital discharge rate Randomised controlled trial, protocol

\section{Supplementary Information}

Supplementary information accompanies this paper at https://doi.org/10 1186/s13063-020-04815-z.

Additional file 1.

\section{Acknowledgements}

The authors would like to acknowledge the kind cooperation of Anesthesiology Research Center, SBMU, Iran for their support. Also, the kind cooperation of the clinical and administrative parts of Taleghani Hospital and Modarres Hospital, both in SBMU, Tehran, Iran is highly acknowledged. In addition, the kind help of Dr Amini Pouya and Dr Rabiei are highly appreciated.

\section{Authors' contributions}

$A D$ and $S R$ conceived of the study. AD, SR, MG, MF, NM, ST, KF, NN, NMA, SB initiated the study design. AD, MG, MF, ST, KF, NN, SB, ANA, AP and MAKK helped with implementation. $A D$ is the grant holder. $A D, S R$ and NM provided statistical expertise in clinical trial design and NM is conducting the primary statistical analysis. All authors contributed to refinement of the study protocol and approved the final manuscript."

\section{Funding}

This research project is funded by the Anesthesiology Research Center, SBMU, Tehran, Iran with grant number 22959. Besides, support was provided solely from institutional and/or departmental sources. The funding body only has an "observation role" in the design of the study and collection, analysis, and interpretation of data and in writing the manuscript.

The surfactant vials would be provided by Tekzima Drug Alborz Company, Tehran, Iran which provided the drugs as a support to the study. The drug was provided as "Beraksurf" as $100 \mathrm{mg}$ in $4 \mathrm{~mL}$ vials. Except for the drugs, there is no relationship between the researchers and the latter company or any other company.

\section{Availability of data and materials}

The corresponding author has access to the final dataset of the trial, and the data will be available on reasonable request (Contact: alidabbagh@yahoo.com).

Ethics approval and consent to participate

Name of ethics committee: Shahid Beheshti University of Medical Sciences, Tehran, Iran.

Ethics committee reference number: IR.SBMU.RETECH.REC.1399.016; Approval date: 2020-03-28, 1399/01/09

I certify that this trial has received ethical approval from the aforementioned ethical committee. In addition, we intend to obtain consent from participants to participate in the study (or from their parent or legal guardian in the case of children under 16).

Consent for publication

Not applicable.

\section{Competing interests}

The surfactant vials were provided by Tekzima Drug Alborz Company, Tehran, Iran which provided the drugs as a support to the study. The drug was provided as "Beraksurf" as $100 \mathrm{mg}$ in $4 \mathrm{~mL}$ vials. Except for the supply of the drugs, there is no relationship between the researchers and the latter company or any other company. 


\section{Author details}

'Cardiac Anesthesiology Department, Anesthesiology Research Center, School of Medicine, Shahid Beheshti University of Medical Sciences, Tehran, Iran. ${ }^{2}$ Immunology Department, School of Medicine, Tehran University of Medical Sciences, Tehran, Iran. ${ }^{3}$ Fellowship of Critical Care Medicine, Anesthesiology Department, School of Medicine, Shahid Beheshti University of Medical Sciences, Tehran, Iran. ${ }^{4}$ Anesthesiology Department, School of Medicine, Shahid Beheshti University of Medical Sciences, Tehran, Iran. ${ }^{5}$ Internal Medicine Department, School of Medicine, Shahid Beheshti University of Medical Sciences, Tehran, Iran. ${ }^{6}$ Fellowship of Cardiac Anesthesia, Anesthesiology Department, School of Medicine, Shahid Beheshti University of Medical Sciences, Tehran, Iran. 'Department of Surgery, School of Medicine, Shahid Beheshti University of Medical Sciences, Tehran, Iran.

${ }^{8}$ Department of Radiology, School of Medicine, Shahid Beheshti University of Medical Sciences, Tehran, Iran.

Received: 14 October 2020 Accepted: 16 October 2020

Published online: 11 November 2020

\section{Publisher's Note}

Springer Nature remains neutral with regard to jurisdictional claims in published maps and institutional affiliations.

- fast, convenient online submission

- thorough peer review by experienced researchers in your field

- rapid publication on acceptance

- support for research data, including large and complex data types

- gold Open Access which fosters wider collaboration and increased citations

- maximum visibility for your research: over $100 \mathrm{M}$ website views per year

At $\mathrm{BMC}$, research is always in progress.

Learn more biomedcentral.com/submissions 